\title{
Multiple Environments: Accountability, Integration and Ontology
}

\author{
Published in A Barry and G Born (eds) (2013) Interdisciplinarity: Reconfigurations of the Social and \\ Natural Sciences, Routledge
}

Gisa Weszkalnys and Andrew Barry

In their book Rethinking Science, Helga Nowotny and her colleagues note that the environmental sciences 'which burst upon the research scene in the wake of the influential environmental movement of the 1970s' are exemplary of what they term a 'strongly contextualized' field (Nowotny et al. 2001: 131). In such a field, research is not directed by government policy (or 'weakly contextualised' in their terms); rather, 'researchers have the opportunity, and are willing, to respond to signals from society' (ibid.). Although we question whether environmental research is necessarily strongly contextualized in the manner described by Nowotny et al., their thesis does point to one key feature of the environment as an object of scientific research. Namely, that the concept of environment does not clearly refer to a specific empirical object or a series of 'well-defined entities' (Anderson and Braun 2008: xiii) but rather to a field of problems whose existence and importance is regarded as self-evident. ${ }^{1}$

Despite what they see as the exemplary character of the environmental sciences, it is striking that Nowotny et al., writing in 2001, found it difficult to come up with a specific example of environmental research that is 'strongly contextualised': 'it is not easy to identify unequivocal examples of strong contextualization, when such examples should also demonstrate what a difference strong contextualization makes' (ibid.: 134). In this chapter, we address this empirical lack, focusing on the work of research institutions that have explicitly addressed the relation between environmental research and 'society' - although this has not necessarily implied, as we shall see, that researchers have directly responded to 'signals from society'. Our analysis of the different, and often competing, motivations and purposes of interdisciplinarity in this field draws on research conducted between March and November 2006 in three different research institutions: the German Öko Institut, the Tyndall Centre for Climate Change Research in the UK, and the Earth Institute located at Columbia University, New York. ${ }^{2}$ In these institutions, along with others, we argue that the growth of environmental research manifests, first, what we have termed a logic of accountability (Barry et al. 2008) that is enacted in diverse forms, and in which the question of which 'society' should be addressed or responded to is itself at issue. ${ }^{3}$ Nonetheless, we argue that we cannot assume that there has been a movement from less to more 'strongly contextualised' research over recent decades. Some research institutions that in the past pursued a self-conscious critique of disciplinary forms of knowledge production have now to some extent been rendered accountable by more conventional forms of academic assessment.

But if the conduct of environmental research has been guided in part by a logic of accountability, it is also thought by many researchers to have been driven by the challenge of the complexity of the environment as an object of research. Viewed in this light it is the environment itself - on account of its complexity, heterogeneity, or the range of its impacts - and not just society or the growing social concern with the environment that is thought to require what is referred to as the integration of

\footnotetext{
${ }^{1}$ In Foucault's terms, the critical importance of the idea of the environment to research in the late $20^{\text {th }}$ and early $21^{\text {st }}$ century can be understood as an event: for a multitude of reasons 'the environment' has come to be regarded as something that 'counts as being self-evident, universal, and necessary' (Foucault 2000: 227).

2 The case studies were selected because they exemplify quite different forms of interdisciplinarity, rather than because they correspond to any generalized type of institution. The field research included about 60 interviews with researchers and, where feasible, observations of meetings, project discussions and similar instances of research in practice. The range of material gathered and the comparison across institutions allowed for rich insights regarding interdisciplinary practices in each institution, as well as the wider context in which these prevailed. Additional interviews were conducted with researchers at the Wuppertal Institut in Germany and at the Oxford Environmental Change Institute. We would like to express our appreciation and gratitude to the staff across all the institutions for having made time in their busy and demanding professional lives to be interviewed and observed for this project.

${ }^{3}$ An analysis of the nature and feasibility of interdisciplinary environmental research in Australia is provided by Strang (2009), stressing the need for greater openness to and integration of critical social analysis.
} 
different methods and concepts, seemingly forcing researchers to move beyond their normative disciplinary commitments. Indeed, for some researchers, the environment has come to be understood not merely as an interface or zone of interaction between the natural and the social, but as a domain that problematises the distinction between nature and society (Halewood 2011; Strathern 1992). In short, we will argue that some instances of environmental research have been oriented by incipient manifestations of what we have termed a logic of ontology as well as a logic of accountability. In this chapter we point to connections between accountability and a transformation of the objects and relations of research; but we also argue that analytically these logics should not be collapsed. Rather than identifying a movement from one mode of knowledge production to another, the chapter offers an analysis of the politics of differences in interdisciplinary forms. The argument is organized in three parts. In the first part, we consider the genealogy of the three institutions, stressing their relation to specific national contexts as well as to wider movements in the environmental sciences. In the second and second part we consider the ways in which the logic of accountability is performed in the research practices and strategies of interdisciplinary institutions. In the third part of the paper we turn to critical importance of the idea and practice of integration to interdisciplinary environmental research, and the relations between some forms of integration and the logic of ontology.

\section{Genealogies}

The concern with the 'society-nature interface' (Castree 2001: 1) implied in contemporary environmental research is not new. It was critical, for example, to the constitution of geography as a discipline which, in Halford Mackinder's famous formulation, was understood 'as the science whose main function is to trace the interaction of man in society and so much of his environment as varies locally' (Mackinder 1962 [1887]). ${ }^{4}$ But if geographers have tended to conceive of the question of the relation between nature and society as internal to the discipline, it seems fair to say that there is something distinctive about the current concern with the necessarily interdisciplinary character of environmental research more generally. In recent decades environmental research has come to straddle an expanding range of interdisciplinary fields and sub-fields including Earth System Science (Wainwright 2009), Sustainability Science (Komiyama and Takeuchi 2006; Turnpenny and O'Riordan 2007), Ecological Humanities (Bird Rose and Robin 2004), Integrated Assessment (Rotmans 1998), Environmental Health, Human Ecology and Conservation Biology (Baird Callicott 2010), Political Ecology (Watts and Peet 2004), Science and Technology Studies (Jasanoff and Wynne 1998; Jasanoff, this volume) and 'human dimensions of global environmental change' (Liverman 1999: 110; Rayner 1992). ${ }^{5}$ The research domains affected by these developments include academy-wide scientific subfields, but also specifically national trajectories of thought such as the 'social ecology' tradition based at the Institute for Social-Ecological Research (ISOE) in Frankfurt/Main (e.g., Becker 2003; Becker and Jahn 2005). In addition, geographers themselves have sought to (re)claim the field of environment for a discipline that during the second half of the twentieth century appeared to be increasingly divided between its 'human' and 'physical' halves (Castree 2005; Harrison et al. 2004, Hinchliffe 2007; Livingstone 1992; Whatmore, this volume). For some environmental researchers, including environmental geographers, it is the inherent relationality of the new 'socialized nature" - where the environment is understood to be simultaneously 'natural' and 'social' - that should be mirrored in research outputs which embody these relations (Hulme 2008). ${ }^{7}$

\footnotetext{
${ }^{4}$ On Mackinder's significance to the formation of the discipline of geography in the UK, see Livingstone 1992.

5 The contribution on 'the environment' in the Oxford Handbook on Interdisciplinarity (2010) points to the difficulty of describing this heterogeneous series of fields, noting that 'to keep this chapter within reasonable limits the discussion of interdisciplinarity will be confined to one self-consciously interdisciplinary trans- (or better meta-) discipline, conservation biology' (Baird Callicott 2010: 495).

${ }^{6}$ The changes that we describe stem from critiques of conventional western conceptions of 'nature' as the opposite of 'culture' and as devoid of human traces (Berglund 1998, Descola and Pálsson 1996; Strathern 1992, Whatmore 2002, Latour 2004).

${ }^{7}$ A similar interrogation of the divide between nature and culture and thus reclaiming of the environment or, rather, 'natureculture' (Haraway 1991) as proper research objects can also be observed in anthropology (e.g., Descola and Pálsson 1996; SCA2010; Viveiros de Castro 1998).
} 
These disciplinary and interdisciplinary movements both followed and existed in conjunction with the emergence of an environmental consciousness, with both scientific and popular expression. It was catalyzed by what were widely experienced as a series of environmental and socio-economic crises throughout the 1960s, 70s and 80s (Agar 2008). These crises were associated variously with the threat of resource depletion and the belief that there were 'limits to growth' (Harvey 2011: 72), the 1973 'oil crisis' (Mitchell 2011: 173-199), the increased occurrence of El Niño and associated droughts (Cane 1986; Zebiak and Cane 1987), a burgeoning awareness of air pollution, pesticides and acid rain (McCormick 1991: 62), and the risk of nuclear accidents (Beck 1992; Nowotny 1976). The growing sense of an interconnected and vulnerable global environment reverberated in a number of key political and scientific gatherings, such as the UN Conference on the Human Environment in Stockholm in 1972 (Liverman 1999: 107), and led to the development of the UN Environment Program as well the establishment of new research institutes including, in the UK, the School of Environmental Sciences at the University of East Anglia and the independent International Institute for Environment and Development (IIED) and, in Austria, the International Institute for Applied Systems Analysis (IIASA). At the same time citizens, institutions and states were increasingly expected to recognize their responsibility for the generation and the solution of environment problems (Agrawal 2005; Grove 1995; Luke 2006), as well as the need to be informed (Barry 2001; Strathern 1999: 68). In other words, society was both conceived as a cause of environmental crises and as a domain in which environmental problems must be considered and solved.

The three environmental research institutions examined in this chapter emerged out of different historical and political circumstances and research traditions, and in each case interdisciplinarity presents a different arrangement of research agendas, objects and actors. One, the Öko Institut, was conceived in the late 1970s as the 'scientific arm' of German environmental citizen groups, and by the early 2000s it had grown into an important independent advisory centre with about 100 employees. The second case study, the Tyndall Centre for Climate Change Research, was established in 2000 as a selfconsciously interdisciplinary endeavour, backed by public funding and distributed across a number of major British universities. ${ }^{8}$ However it also built on a history of interdisciplinarity at the University of East Anglia (UEA), dating back to its founding in the 1960s. Our third case study, the Earth Institute at Columbia University, involved yet another kind of experiment. It was set up in the mid 1990s by Michael Crow, then the university's Vice Provost, as an experiment in institutional innovation, and aimed to configure a new kind of knowledge for the $21^{\text {st }}$ century, drawing together existing research centres at Columbia.' This institutional experiment apparently faltered after only a few years of existence, and was given new life with the arrival in 2000 of the current director, Jeffrey Sachs, who gave the institute a distinct new vision, linking environmental to developmental concerns (e.g. Sachs et al. 2009). While at the Earth Institute interdisciplinarity has come to be considered a tool for solving so-called 'real world' problems, and at the Tyndall Centre interdisciplinarity is associated with a concern to move beyond a largely natural scientific understanding of climate change, the Öko Institut is portrayed by its staff as having pioneered the future-oriented mode of transdisciplinarity - a concept that subsequently became central to the work of Nowotny and others. ${ }^{10}$

\footnotetext{
${ }^{8}$ Notably, the Tyndall Centre drew support from three different UK Research Councils spanning the natural and social sciences: the EPSRC (Engineering and Physical Sciences Research Council), the ESRC (Economic and Social Research Council) and the NERC (Nature and Environment Research Council). The Tyndall Centre brought together research groups and centres at the University of East Anglia, Southampton, Manchester, Cranfield, Sussex and Cambridge Universities, together with the Rutherford Appleton Laboratory and the NERC Centre for Ecology and Hydrology. ${ }^{9}$ Michael Crow had conducted extensive research on organizational structures and innovation processes in the US (Crow and Bozeman 1998). Following his directorship of the Earth Institute he became President of Arizona State University, where he sought to implement his vision of post-disciplinary research on a larger scale (Crow 2006; cf. Frodeman et al. 2010; Jasanoff, this volume).

${ }^{10}$ Something of the intensive circulation of discourses among our research sites is indicated by the fact that the idea of Mode-2 knowledge production was also explicitly referred to by informants at the Tyndall Centre. Nonetheless, the term transdisciplinarity is seldom used in policy circles in the UK, while it is widely used in the German-speaking world, including by the German government.
} 
The first of our case studies, the German Öko Institut, has its origins in a political situation that also saw a proliferation of environmental and related protest movements across Europe (Doherty 2002). The institute was founded in 1977 in conjunction with a conference entitled 'The Role of the Scientist in Society'. At this time it was conceived, drawing on a self-consciously ethical and bottom-up agenda, as a kind of service provider, delivering scientific evidence to buttress the environmental protests led by several civic action groups in southwestern Germany (Roose 2002: 17-18). These groups were involved in anti-nuclear protests focused on sites such as Wyhl in southern Germany and Biblis near Frankfurt. They brought together concerned citizens and students keen to bolster civic protest with scientific argument. The notion of a potential relation - or, rather, criticism of the perceived lack of a relation between science and society was key. The aim was to develop a 'counter-science' or 'counter-expertise' (Gegen-Wissenschaft) (see also Nowotny 1976: 3, 1979). ${ }^{11}$ These groups denounced the apparent complicity of renowned scientists in both the troubling practices of large chemical-industrial corporations and the establishment of the nuclear energy industry in Germany, while recognizing - as Ulrich Beck came to argue - that 'the diagnosis of [ecological] threats and the struggle against their causes is often possible only with the aid of the entire arsenal of scientific measurement, experimental and argumentative instruments' (Beck 1992[1986]: 162-163; see also Berglund 1998).

The American Union of Concerned Scientists in the US may have been an early role model for these developments; but in the German context the actors involved, some of whom are today researchers at the Öko Institut, perceived themselves very much as pioneers. ${ }^{12}$ In 1970s Germany, the practice of popular participation - that is, the inclusion of a variety of (conflicting) views in policy and planning was still in its infancy. In these circumstances, Öko Institut researchers and their allies demanded a new type of accountability and responsiveness to society on the part of the state. By implication, they saw themselves as using their scientific expertise in the name of society. During the Chernobyl crisis of 1986, for example, institute researchers, who had already established themselves as outspoken critics of nuclear energy, offered much-needed advice from a single telephone line in a small office in Darmstadt, a mid-sized German town, to a panicked and largely ill-informed population. Today, this intervention is invoked as a highly significant moment: it resulted in the establishment of a German environmental ministry and underscored the institute's raison d'être.

In this evolving situation, a new interdisciplinary space was constituted, existing outside and alongside academic infrastructures and conventions. In a double sense, the interdisciplinary research practices opened up by the Öko Institut were conceived antagonistically to dominant forms. First, they were at odds with disciplinary scientific practice, bringing together the natural and social sciences around redefined research objects and questions. Second, they were understood as standing in self-conscious and vocal opposition to the conservatism, hierarchies, political networks and persistent links to industry that were considered to corrupt German academia. In short, the institute was expected to embody an important shift towards non-academic, although not necessarily commercial, forms of knowledge production, in which the production and circulation of interdisciplinary knowledge could flourish freely. In addition, a number of new institutions embodying altered research models began to spring up. For example, in 1991 the government of North Rhine Westphalia added a new part to its Science Centre named the Wuppertal Institute for Environment, Climate and Energy Research. This interdisciplinary institute can be seen as a kind of imitation of the template provided by the Öko Institut, albeit under improved conditions, notably continuous public funding. The Wuppertal Institut was given added conceptual direction by its founding director, Ernst Ulrich von Weizsäcker, who in 1989 laid out his thoughts regarding the necessity for a new type of politics coupled with a new type of research in an influential publication, Erdpolitik, (Earth Politics). The ideas contained in this book reflected a broader shift in German environmental politics: significantly, it included a call for

\footnotetext{
${ }^{11}$ Close relations existed between these groups and the wider German anti-nuclear movement, specifically the protests around Wyhl which centred on the occupation of the site of a planned nuclear power plant. An important element in this occupation was the construction of a building for a variety of events including what was called a 'people's university' (Volksuniversität).

${ }^{12}$ Guggenheim (2006) suggests a similar trajectory of environmental consultancies in Switzerland.
} 
interdisciplinary research that would bring together the 'two cultures' characteristic of academia around new themes, in an effort to shape $21^{\text {st }}$ century politics and culture (Von Weizsäcker 1997: 245). In the $\mathrm{UK}$, wider debates about the problems resulting from the two cultures had been prevalent since the 1960s, and influenced the pedagogic practice and institutional form of new Universities established in the period, such as UEA and Sussex. However, there was no UK equivalent to the Öko Institut, which had been established outside of the University system.

In the 1980s, the emerging concern with ozone depletion, global warming and the decrease of tropical forest cover rendered 'climate' - an area of research previously subsumed under the heading of meteorology (Bray and von Storch 1999: 439; Edwards 2010; Miller and Edwards 2001) ${ }^{13}$ - an object of study in its own right (Liverman 1999: 108). This shift was buttressed by several landmark conferences, including the first international conference on the 'greenhouse effect' held at Villach, Austria, in 1985, ${ }^{14}$ the subsequent meeting of climate scientists in Toronto in 1988, and the creation of an Intergovernmental Panel on Climate Change (IPCC), which delivered its first report in 1990 (Schröder 2010). ${ }^{15}$ In Britain, the establishment in 1990 of the government-funded Hadley Centre can be seen both as a direct result of these developments and as a manifestation of the government's increasing recognition of the importance of environmental issues, particularly following an influential speech by Prime Minister Margaret Thatcher to the Royal Society in 1988 (Whitehead et al. 2007: 138). ${ }^{16}$ However, in the late 1980s and early 1990s, the notion of interdisciplinarity as a means of integrating the social aspects of the emergent problems with natural scientific data was marginal to the agenda of climate change research in the UK and elsewhere. In our interviews, researchers at the Center for International Earth Science Information Network at Columbia, who had been involved in the 1980s in a rethinking of the U.S. Geosphere-Biosphere Program, commented on the reluctance on the part of natural scientists to embrace the social sciences, which were considered to be relatively imprecise and messy. Significantly, 'human factors' were quite literally represented as a black box in the diagrams visualizing the interrelations between the different spheres in the context of the Global Change program (Rayner and Malone 1998c: 35) and in the early formulations of Earth-System Science (Wainwright 2009: 153). Nonetheless, the view that climate change represented a considerably more complex research challenge than what had previously been encountered as environmental problems such as nuclear power or acid rain - was quick to gain hold. Increasingly, through the 1990 s and early 2000 s, it became apparent to many researchers that climate change would require not just a global and longer-term research response, but that it would have to draw together in some way the contributions of both the natural sciences and social sciences (Rayner and Malone 1998a).

In the UK, the formation of the Tyndall Centre in 2000 was the most visible expression of the increasing conviction that the social sciences, as well as the natural sciences, were needed in order to make progressive inroads into the study of climate change. Yet the institutional development of the Tyndall Centre also reflected the longer history of interdisciplinary work on the environment at UEA in Norwich. In particular the zoologist Solly Zuckerman, Chief Scientific Advisor to the Labour

\footnotetext{
${ }^{13}$ In the area of interdisciplinary thinking about climate change, an important publication was the edited collection, 'Climate Impact Assessment' (Kates et al. 1985), assembled by the international Scientific Committee on the Problems of the Environment (SCOPE).

${ }^{14}$ This conference 'established the hegemony of the natural sciences in the way climate change would subsequently be presented to the world' (Hulme 2008: 6).

15 A number of environmental research institutions were founded at this time, including The Beijer Institute, Sweden (1977/1991); the Norwegian Institute for Nature Research (NINA, 1988); the Stockholm Environment Institute (1989); the Frankfurt Institute for Social-Ecological Research (ISOE, 1989); and the Regional Environmental Centre for Central and Eastern Europe (1990). The ISOE now describes itself as "an innovative scientific think tank [that] undertake[s] transdisciplinary research for society, policy makers and industry" (emphasis added) http://www.isoe.de/en/isoe/ (accessed 4/1/12).

16 The Prime Minister formulated the problem in natural scientific terms: 'In studying the system of the earth and its atmosphere we have no laboratory in which to carry out controlled experiments.... We must ensure that what we do is founded on good science to establish cause and effect' http://www.margaretthatcher.org/document/107346 (accessed 4/1/12).
} 
government of Harold Wilson, played a key role in promoting the formation of an interdisciplinary research agenda in the environmental sciences in the University. Zuckerman wrote in a letter:

' $[\mathrm{f}$ one had it in mind to do something absolutely new and fresh in science I am wondering whether Norwich could not embark in its faculty of Science, on a Division of Environmental Sciences - meteorology, oceanography, geology, conservation etc. If it were, I am quite certain that nobody would ever be able to say that scientists were trained in a narrow way. Conservation would lead to the social sciences, population studies etc. and so over into the preoccupations of at any rate one sector of those who teach the humanities'. ${ }^{17}$

Reflecting Zuckerman's vision for the environmental sciences, the first Director of the University's Climate Research Unit, Hubert Lamb, drew on historical sources such as grain price records and diaries as well as more conventional forms of scientific data in developing an analysis of climate change in the modern world (Lamb 1982: 89). While the development of the Centre can be understood as a manifestation of the long-standing interest in the environmental sciences at UEA, it also coincided with a period in which the UK research councils and policy-makers came to stress both the value of interdisciplinary research and the importance of attending to the needs of users and stakeholders more generally (HM Treasury 2006: 6; see also Doubleday 2007; Lowe and Phillipson 2009). In these circumstances, the constitution of the Centre embodied an agonistic relation to existing natural scientific approaches to climate change research, while also resonating with broader trends in UK science and technology policy.

If the Tyndall Centre placed explicit emphasis on the value of interdisciplinarity or transdisciplinarity, ${ }^{18}$ notions of interdisciplinarity and transdisciplinarity were of much less significance to the public identity of the Earth Institute, which defined itself largely in terms of the range of global policy problems that its research was intended to address. When accepting the directorship of the Earth Institute, Jeffrey Sachs could build on Columbia's expertise in earth and climate sciences at the Lamont Doherty Observatory, and on existing cross-disciplinary research centres. These centres had developed progressively throughout the 1980s and 1990s, and were now brought under the institute's umbrella. They included, for example, the Center for International Earth Science Information Network (CIESIN), which was originally established at the University of Michigan in 1989 and became a centre within the Earth Institute in 1998, and the International Research Institute for Climate and Society (IRI) - previously the International Institute of Climate Prediction - which succeeded in attracting substantial funding from the National Oceanic and Atmospheric Administration. Under Sachs's directorship, problem-oriented research became prioritised. No longer an experiment in institutional organization, as it had been under its founding director Michael Crow, the Institute now aims to respond to global policy problems, linking the environment to broader development concerns, particularly in low-income countries. The shift in focus is also observable in Sachs's own research and policy contributions, which over the last decade have steadily placed greater emphasis on the close connections between apparently geographic, environmental and climate-related problems, such as malaria, and prospects for economic growth and poverty alleviation (Sachs 2000, 2003).

The growing importance accorded to interdisciplinary research on the environment has come not just with organizational and institutional implications but also with implications for the identity of researchers. At the Öko Institut, the Earth Institute and the Tyndall Centre, in particular, the institutionalization of interdisciplinarity was accompanied by explicit efforts to create a new type of researcher. The developments outlined above suggest that this ability to integrate the insights of the

\footnotetext{
${ }^{17}$ Letter to Sir Christopher Ingold (nd), quoted in Krohn (1995: 591).

${ }^{18}$ In the original proposal for funding, it was argued that: 'The Tyndall Centre Research Programmes have been deliberately chosen to require the integrated, interdisciplinary approach that the climate change problem demands' (Tyndall Centre 2000: 44, emphasis in original). More recently the Tyndall Centre has come to define its objectives as:

'To research, assess and communicate from a distinct trans-disciplinary perspective, the options to mitigate, and the necessities to adapt to, climate change, and to integrate these into the global, UK and local contexts of sustainable development' (emphasis in original) http://www.tyndall.ac.uk/about/objectives (accessed 4/1/12).
} 
natural and social sciences and to think across disciplinary boundaries was increasingly seen as desirable on the part of environmental researchers. The Earth Institute, for example, runs a fellowship programme aimed to equip postdoctoral researchers in the natural or social sciences with broad skills gained through working with multidisciplinary research teams. Similarly, participants at the annual Tyndall Centre conference in November 2005 were expected to place themselves somewhere in an interdisciplinary space represented by a triangular diagram, the three vertices of which were associated with engineering, the natural sciences and the social sciences. In principle, a true 'interdisciplinarian', it was suggested, might find themselves somewhere at the centre of this figure, although in practice a capacity to be more interdisciplinary was something that could be acquired over time. As Simon Schaffer (this volume) reminds us, the association is often made between the constitution of (academic) disciplines and the cultivation of discipline. The new interdisciplinary centres of environmental research embodied the belief that the capacity to be interdisciplinary might require cultivation too (Tompkins 2005).

\section{Accountability and Innovation: Useful Science}

As noted in the Introduction to this volume, calls for greater inter- or transdisciplinarity in recent decades have often been linked to a heightened concern with the accountability of scientific research (Nowotny et al. 2001; Strathern 2004, 2005). In this sense, accountability towards varied constituencies was felt to matter in all the institutions that we examined. In this section, we stress the centrality of the logic of accountability, while indicating the multiplicity of ways in which it is enacted.

At the Öko Institut, the prevalent mode of interdisciplinarity - or transdisciplinarity' in the researchers' preferred terminology - was understood as a kind of pragmatic response, one that was in line with the critique of 'mainstream science' and the reconceptualization of the environment as an inherently politicized realm outlined earlier. For Nowotny and her collaborators, the development of Mode-2 knowledge production entails a new 'social contract' for science. Interdisciplinarity and transdisciplinarity are crucial, in this view, because they are reckoned to be capable of dealing with the increased uncertainty characteristic of our times and with meeting the need for a more open, inclusive and 'contextualised' science. The authors sketch an evolution from the closed science lab to the open knowledge agora, such that the latter is conceived as a 'space where science meets and interacts with' the public, government institutions and other important agents (2001: 260; see also Callon et al. 2001; Funtowicz and Ravetz 1993 ). Öko Institut researchers largely recognized themselves in this definition of transdisciplinarity, which they claimed to have anticipated in their own practice, and which they achieved through the involvement of policy-makers, citizens and industry in the production of knowledge, or through their mediation of already ongoing discussions between stakeholders (cf. Bergmann et al. 2005). The Öko Institut did not invent the term, but it was seen by its researcher members as one of the examples on which Nowotny and her colleagues may have based their analysis of Mode-2 knowledge production.

At the Earth Institute, in contrast, the relations between interdisciplinary environmental research and society were less explicitly politicized than at the Öko Institut. They were also understood in a variety of different ways, ranging from an instrumentalist view of the social sciences as a bridge to key stakeholders, to attempts to develop possibilities for integrating environmental and socio-economic data, for example through the use of Geographical Information Systems (GIS). More critical viewpoints urging a rethinking of the theoretical underpinnings of environmental studies, however, have tended to be marginalized at the Earth Institute. ${ }^{19}$ Indeed the institute's primary mission, in forging new links between science and society, is not to rethink the distinction between science and non-science in general, nor to develop a form of counter-expertise (Beck 1992), but to make science useful to the concerns of policy-makers and interested publics. In effect, the Earth Institute is expected

${ }^{19}$ Interview, New York, June 2006. 
to engage not just in the production but also in the mediation of knowledge (Osborne 2004). ${ }^{20}$ At the International Research Institute for Climate and Society (IRI), for example, founded in the mid 1990s and now part of the Earth Institute, it is claimed that the usefulness of scientific research is achieved through the forming of partnerships with local people, decision makers and experts. As one researcher observed: 'one of the things that drives the multidisciplinarity of this institution [IRI] is the idea that if you have an innovative technology it's not enough to just have the technology, it's to get it out there and make it useful. ${ }^{21}$ The aim was to turn scientific knowledge into information that would be directly useable in the specific locations where it is needed, creating 'solutions for problems in public health, poverty, energy, ecosystems, climate, natural hazards and urbanization'. 22 The partnerships envisaged were thought to enable an immersion of the scientific research institute in local problems. The assumption was that scientific knowledge and technology were rarely useful in themselves, as evinced by high non-take-up rates. In this context, the interpretation and communication of scientific research by social scientists were expected to enhance society's capacity to act upon climate fluctuations.

Making science 'truly useful' was also an explicit goal at the Tyndall Centre (Hulme and Minns 2006). In practice this goal was addressed in diverse and contrasting ways, depending both upon the research problem and the research group. In some instances, the aim of Tyndall research was to inform (global) policy institutions through the development of rigorous interdisciplinary climate change research that incorporated the work of both social and natural scientists. For example, when addressing the question of the constitution of 'dangerous' climate change it was thought necessary to consider it both from an 'external' scientific viewpoint and from an 'internal' analysis of individual or collective human experience. For Tyndall researchers concerned with this problem, both forms of analysis should contribute to public policy, for 'public policy institutions need to make this decision [about what constitutes dangerous climate change] on behalf of global society and act on its implications' (Dessai et al. 2004: 11). However, Tyndall researchers also sought to develop closer relations with political institutions, stakeholders and civil society. One researcher, for example, described his approach as involving a 'civil-society peer review process' specifically tailored for each project, rather than relying on a single overarching advisory group in its initial phase. Another Tyndall researcher concerned with problems of climate change adaptation and mitigation emphasized the value of engaging not just with policy-makers and governments but with a wide range of social groups, including civic associations and local populations (O'Riordan 2004). In this respect, the Tyndall Centre's approach to research reflected wider trends in the conduct of environmental governance. For while the environment was increasingly understood as an object of interdisciplinary research, this development occurred in conjunction with a greater presence of NGOs and other non-state actors in the development of environmental policy, which became increasingly apparent following the 1992 Rio Earth Summit (Liverman 1999: 111).

Nowotny et al. capture something of this diversity of forms of 'contextualisation': from a political notion of the accountability of science, prompted by a kind of democratic impulse and by movements such as those that fuelled the founding of the Öko Institut, to the problem-oriented conception of the utility of scientific knowledge embodied in the Earth Institute (Nowotny et al. 2001: 97). But although Nowotny and her co-authors identify and promote values of accountability, contextualization and transdisciplinarity, they have had less to say about the difficulties confronting institutions and researchers that, in adopting these practices, have been expected to demonstrate the worth and the rigour of their research to others. In this respect, the cases of the Öko Institut, the Tyndall Centre and the Earth Institute are all instructive.

\footnotetext{
20 The Director of the Earth Institute, Jeffrey Sachs, has called for 'A global network of respected ecologists, economists, and social scientists working to bring scientific knowledge to decision-makers and to the public [that] can clarify the state of scientific knowledge, help to mobilize needed research, and defeat the obfuscation led by vested interests' (Sachs 2006: 1002).

${ }^{21}$ Interview, New York, June 2006.

22 http://www.earth.columbia.edu/articles/view/1791 (accessed July 2011).
} 
In our research we found that while the Earth Institute and the Tyndall Centre needed to be explicit about their efforts to ensure usefulness and accountability, at the Öko Institut this seemed to be a less pressing concern. In a sense, however, this is unsurprising, for the Öko Institut had already built 'society' into its organizational design. The institute was set up as a civic association - a Verein - with about 3,000 members, 230 of which were active members with voting rights, including the institute's staff. For many years, the assumption was made that this organizational form provided a 'societal anchoring' to the research conducted by the institute. Legally, a Verein is required to bring public benefits; and there is a strong sense that all research at the institute is conducted in and for 'society', as represented by the members. However, this 'embodiment' of society by the institute may seem less obvious today. During the period of our research, the Verein members still met regularly to develop suggestions for the institute's research direction. But partly due to the recognition that Verein membership was comprised only of a small segment of society, partly due to a stagnation of membership numbers since the mid 1990s, and partly because the institute is no longer financially dependent on membership fees, ${ }^{23}$ there were tentative calls for a revision of its organizational form.

The Öko Institut had also conducted a long-drawn out internal participatory process to formulate a Leitbild, a mission statement, for its operations. It emphasized that the significance of their research and science was decidedly not value-free. The institute's science was deemed to embody values of independence, transparency and creativity, as well as respect for each other and for collaborators, without however foregoing objectivity. ${ }^{24}$ In addition, new concepts were invoked to convey the sense of society being folded into Öko Institut research. The concept of transdisciplinarity, for example, as indicated above, is defined by the institute as a type of research that involves a meaningful connection to relevant political, economic and social actors. While there was little sustained theoretical debate on transdisciplinarity at the Öko Institut during our fieldwork, the presence of an ethnographer (Weszkalnys) had the effect of prompting animated discussions over lunch about the content and definition of the term. Transdisciplinarity had become a deliberate strategy with which to ensure innovative and accountable science. The adoption of the term in the institute's self-descriptions indicated a new phase in its development, in which the relation to 'society' or 'the public' had become increasingly formalized. This formalization, in turn, brought its own problems. First, a major 'user' of knowledge, identified directly and indirectly in the writings of public funding bodies and government strategy papers, is industry. In Germany as elsewhere, forging links with industry is widely considered to be a way to foster innovation and to cut public spending. Nowotny et al. similarly suggest that closer links between academia and the market are part of the move towards Mode- 2 science. This assessment, however, overlooks important moral ambiguities and worries about the potential loss of scientific autonomy.

Moral ambivalence regarding the encroachment of political interests into the Öko Institut's independent research was pronounced at the time of our study. Such ambivalence could be discerned where close relationships to industry - in the form of clients commissioning new projects - are part of the everyday operations and, as such, considered valuable and indispensable. As one of the founding members explained, at the initial stage of the institute's operations, some researchers got involved less for environmental concerns than out of an anti-statist impulse. This was at a time when the so-called 'phalanx of state and industry', ${ }^{25}$ whose interests were seen as inextricably entwined, formed a key target of the civic protest movements that also motivated the institute's creation. Thus, although the environmental movement and the civic movement of 1968 with its neo-Marxist ideas developed largely separately in Germany, in the context of the institute and its individual actors they could not readily be kept apart. A more differentiated view of the institute's major 'antagonists', including industry and state, has gradually developed. ${ }^{26}$ Today, providing advice and preparing reports for chemical companies is a

\footnotetext{
${ }_{23}$ Membership fees in 2005 represented only around $€ 140,000$ of the Öko Institut's $€ 7$ million annual budget.

${ }^{24}$ Interview, Freiburg, May 2006.

25 Interview, Darmstadt, May 2006.

${ }^{26}$ To protect its hard-earned influence, Öko-Institut researchers seem largely to refrain from making the kinds of public statements that would have been typical of 1980s counter-science and that some of its membership might still like to hear.
} 
regular occurrence, but it still invites comment (Ewen et al. 1997). In May 2006, for example, at the time of fieldwork for this study, a former economist for the large chemical manufacturer Hoechst, a one-time 'enemy', was elected into the Verein's council. There is a sense of having 'arrived in the mainstream,' as one researcher put it, emphasizing that this was a welcome transformation that the Öko-Institut has helped to bring about. ${ }^{27}$ While funding by business and industry has become significant and is generally accepted and seen as desirable in the institute, the entanglements of market, politics and academy, private interests and the public good, are experienced ambivalently. Assertions of autonomy and independence could lack credibility where specific 'societal interests' enter in the form of grants, or governance, and accompanying expectations. In the minds of some researchers and commentators, the line between strongly contextualised outputs and partisanship or bias may be very fine indeed. By becoming more useful, research also risks becoming more open to the political agendas of funding bodies, whether they are companies, NGOs or governments (Monbiot 2006).

\section{Evaluation and Assessment}

More generally, the researchers that we interviewed across the different institutions recognized assessment as a major challenge for present-day interdisciplinarity; for if the research processes and outputs are so innovative and different from established and canonic science, then who is able to evaluate them? And what are the appropriate means to measure and compare efforts to engage with 'society'? These questions were posed particularly acutely by researchers at the Earth Institute who, if their positions were not funded by 'soft' money, usually held positions within Columbia University departments and were therefore subject to the tenure track system of review. Like the formal research assessment procedures carried out periodically in British universities, the tenure track system is considered to revolve around disciplinary categories of evaluation compounded, as several interviewees noted, by Columbia's 'Ivy League' status. Junior and untenured interdisciplinary researchers were seen to face especially difficult predicaments in this context, where strong disciplinary traditions are characteristically upheld and interdisciplinary ventures devalued (Lamont 2009).

The Tyndall Centre experienced parallel but wider problems of evaluation and legitimation. Tyndall staff found that their efforts at establishing interdisciplinary practice risked being disregarded at the end of the Centre's first five-year phase of operation. Although the Centre received a glowing assessment by its external reviewers, who applauded its successful interdisciplinary accomplishments, a bid for continued funding to the UK Research Councils resulted in a drawn-out process of writing, review, attempted justifications and interviews. The outcome of this process was that Tyndall was funded only for a further three years, at a lower level than had previously been assumed and than the Centre thought appropriate (House of Commons 2006a: question 253, 2006b). Some Centre staff were perplexed and dissatisfied with the way the Councils handled the review process, perceiving the outcome as an attack on interdisciplinarity despite the rhetoric regarding its value. ${ }^{28}$ They also felt that there had been no identifiable criteria to assess the new bid, or that the criteria applied were inappropriate or simplistic - such as the number of peer-reviewed journal articles. The range of knowledge-transfer activities in which the Centre had successfully engaged, they argued, was not captured in this process (House of Commons 2006b: 3.3). In a memorandum to the House of

In a sense, the institute has opted pragmatically for a gradual effacement of its more radical stance in order to gain influence in state politics. As one of our interviewees explained, if Öko Institut researchers were seen to make too controversial comments in public, for example, on sensitive issues such as nuclear energy, this could easily lead to their exclusion from governmental policy advisory committees where such partiality is considered inappropriate. 'Not everything that has publicity value is also politically effective,' he concluded.

27 The scepticism can be mutual. Companies are reluctant to cooperate with an institution entangled with environmental NGOs or openly propounding politicized environmental views. Given these pressures to perform its disentanglement from its politicised earlier days, the Öko Institut is keen to demonstrate its respectability, neutrality and credibility in its publicity through long lists of references from commissioning bodies - both public and private. Indeed, the institute can now lend credibility to a company and its products, although researchers emphasize that they do not allow the institute's name to be used for advertising purposes.

${ }^{28}$ The point was taken up in the editorial of Nature (2006). For an account of the then Labour government's stress on the value of interdisciplinary research see House of Commons (2006). 
Commons Select Committee on Science and Technology, the Centre noted the difficulty of finding suitable performance indicators for interdisciplinary research:

Inter-disciplinary research in policy sensitive areas is difficult to fund, difficult to do and difficult to evaluate. It raises issues of learning and interactivity, of capacity building, of working within conventional academic and funding structures designed for a different ear, and of finding powerful and appropriate performance measures (for purposes of accountability). Yet the potential contribution of interdisciplinary research to the development of evidence based policy surely requires that these difficulties are overcome. (ibid.: 1.2)

During the early years of the Centre's development, Tyndall researchers had stressed the importance and value of interdisciplinarity, but in the context of the existing organization of British university research funding, this value was not always easy to recognize. The research councils, in particular, embody a commitment to peer review, which tends to lead to the dominance of disciplinary modes of evaluation. As Mike Hulme, the former Director, articulated:

There is an instinct within research councils in Swindon and also an instinct amongst the professional academics who advise research councils, do peer review, that is still innately disciplinary. There are some individuals who are exceptions to that but there is a natural instinct still, I feel, both organisationally and individually within the academic community, and that makes it hard, sometimes, for the value and the benefit of interdisciplinary research to be properly recognized (Hulme in House of Commons 2006a: question 254).

In contrast, as an environmental consultancy, the Öko Institut operated largely on terms independent of those applied to university-based research (see also Guggenheim 2006). However, there were important exceptions. In a bid to receive additional funding, the institute applied to the German Federal Ministry for Education and Research to fund certain projects, in competition with universitybased research outfits. A concept of transdisciplinarity was part of these funding programmes. Öko Institut researchers thus found themselves in a position of having to meet the Ministry's stipulations about transdisciplinarity, a practice which - as we have mentioned - they themselves claim to have pioneered. Indeed, in Germany, Nowotny et al.'s account is woven into research programmes via its consumption in the research and policy sectors. For example, the social-ecology research programme of the ISOE, now taken up by the Federal Ministry for Education and Research, is self-reflexively described as indicative of a 'mode- 2 knowledge production' which aims to offer problem-oriented, transdisciplinary research situated at the interface of science, politics, the market, and the public (see also Becker 2003; Becker and Jahn 2005; Bergmann and Jahn 2008; Jahn 2003). As transdisciplinarity is transformed from 'mere' descriptor of research practice into a prescriptive research model, Öko Institut researchers have had to change their practice partly to respond to evolving expectations. ${ }^{29}$ Instead of bringing about 'societal change', the researchers funded by such public research programmes are increasingly under pressure to publish the results of their work in relevant academic journals and publications in order to attain academic recognition. ${ }^{30}$ As with the Tyndall Centre, and ironically, traditional academic outputs are gaining a growing importance in rendering the institute 'accountable'.

\section{Integration, Participation and Ontology}

Despite the foregoing, it would be a mistake to think that interdisciplinarity in environmental research has been driven primarily by a desire to make research more accountable and/or useful. For at the same time, and sometimes in tension with this logic, environmental researchers have also argued that it is the nature of their research object, the environment, which requires the development of an

\footnotetext{
${ }^{29}$ Arguably, the impact of these kinds of funding programmes remains relatively negligible in financial terms, constituting only about 4\% of the institutes overall annual budget in 2005/6 (interview, Freiburg, May 2006).

${ }^{30}$ However, the degree to which the institute should be seen to pursue this type of research, and to what extent resources should be set aside to permit the dissemination of research results in peer-reviewed academic journals, remain contested.
} 
interdisciplinary practice. That is, the environment is seen as a hybrid research object containing both nature and society (eg Acutt et al. 2000). Yet while this is so, the question of how it is possible to research such a hybrid object was far from settled in the three institutions. For many of the environmental researchers, the problems posed by the hybridity of the environment were primarily organisational and methodological, requiring contributions from both natural and social scientists. However, for others, the conduct of environmental research potentially posed more profound challenges, challenges that we will argue are ontological as much as they are technical or organizational. In making this argument, we recognise that environmental researchers would not themselves consider the problems that they address to be ontological. Nonetheless, in what follows we analyse the variety of existences of a key term - 'integration' - used by the research organizations that we studied to reflect the 'new' hybrid research object and to work across disciplinary divides (Tansey 2009); ${ }^{31}$ and in doing so, we point to the incipient manifestation in some of these practices of what we have called a logic of ontology.

While the notion of integration is widely used in the field of environmental research, it can refer to a remarkably broad array of practices, ranging from the analysis of causal chains leading to environmental problems, to the spatial integration of social and environmental data, to the involvement of lay experts in the research process. In this section, we outline a number of prevalent integration practices. Our discussion shows that instead of bringing together nature and society into a neat and coherent whole, integration offers a number of pragmatic solutions to the problem of the complexity and heterogeneity of the environment and the uncertainty of its future development. At the same time, in its diverse forms, integration is best understood as a practice or process rather than an end result. In the institutions that were the focus of our analysis we identify five broad forms of integration practice, which evolved progressively over time and are not necessarily mutually exclusive: problem-oriented research, data integration, modeling, user involvement, and scenario building.

The first form is evident in those research activities that proposed interdisciplinary integration as an appropriate method to respond to certain kinds of complex, multi-dimensional research problems. In order to provide an in-depth and comprehensive investigation of the problem of arsenic groundwater contamination in Bangladesh, for example, researchers at the Earth Institute set up interdisciplinary research groups capable of studying both the scientific nature of the problem and its environmental impacts and associated socio-cultural factors and consequences (eg Argos et al. 2007). This integration practice can be equated with a problem-oriented and pragmatic approach to interdisciplinarity. Earth scientists and public health experts brought together their scientific data and social knowledge in this case in what was described by institute staff as an exemplary case of interdisciplinary collaboration.

Yet instead of overcoming the perceived limitations of disciplinary approaches, integration practices of this kind may also result in unanticipated tensions and questions, thus opening up additional (and not always welcome) avenues for research. The interdisciplinary encounter, and attempts at integration, may even generate acute 'perspectival disparities' (Weszkalnys 2010: 154) that can threaten a unified understanding of the research problem. The increase in 'complexity' that is desired by adding social scientific insight may be perceived to hinder the accessibility of research outputs, as discussed above, to broader constituencies of potential stakeholders or users (Strang 2009: 7-11). It may also cause tensions within the research group; thus, a geographer interviewed for this research observed: 'where I see the collisions is when people really sit down to share theory and methods. The scientists suddenly realize that many social scientists think that human behaviour isn't predictable. That, to me, is one of the biggest collisions in interdisciplinary work ${ }^{32}$ A further problem with attempted integration turns on

\footnotetext{
31 A notion of the capacity of integrative approaches and models to reconcile various disciplinary conventions can, as noted in the volume's Introduction, be found more generally in accounts of interdisciplinarity. For instance, Boix Mansilla et al. (2006: 70) claim that interdisciplinary research may be viewed as 'a form of inquiry that integrates knowledge and modes of thinking from two or more disciplines or established fields of study to produce a cognitive or practical advancement (eg. explain a phenomenon, create a product, develop a method, find a solution, raise a question) that would have been unlikely through single disciplinary means'.

${ }^{32}$ Interview, Tyndall Centre, 2005.
} 
differences and tensions between social scientific perspectives. When stressing the importance of social scientific research on climate change, Rayner and Malone, in Climate Change and Human Choice (1998), broadly distinguish between two schools: a quantitative-descriptive school, on the one hand, and a qualitative-interpretive school, on the other. Wolfgang Sachs, sociologist and senior researcher at the German Wuppertal Institute, invoked a comparable distinction when interviewed for our study. He noted that in interdisciplinary projects the division between the quantitative and qualitative schools, or what he termed the counting and narrating approaches to social science, may seem more significant even than those between the natural and social sciences (see also Sachs 1995).

Arguably, there has been a tendency to consider quantitative social science data to be more valuable as it appears to be more readily integrated with natural scientific data (Adger et al. 2005: 2). And indeed, preconceptions regarding the imprecision or lack of scientificity of the qualitative social sciences are not uncommon. Yet, while in the majority of cases the subordination-service mode of interdisciplinary integration (Barry et al. 2008; Barry and Born, this volume) would seem to privilege the 'hard sciences', occasionally, collaboration may be such that social scientists define the nature of the research problems. In the case of the International Research Institute (IRI) for Climate and Society at Columbia, for example, climate scientists felt that the social scientists' delineations of what kinds of knowledge about climate change would be useful for people had begun to dictate the direction of their scientific enquiries. On the other hand, other Earth Institute researchers claimed that the anthropocentrism of the social sciences functioned as an obstacle to their interdisciplinary endeavour. Certain social theoretical approaches, occasionally labelled 'constructivism', were rejected as incompatible with the applied aims of interdisciplinary environmental research. In other words, the narrative of interdisciplinarity as the harmonious integration of disciplinary approaches - one that we frequently encountered - ignores long-standing preconceptions, conflicting epistemologies, and lines of division existing across and within disciplines, making for seemingly incompatible 'epistemic cultures' (KnorrCetina 1999; see also Bensaude-Vincent and Stengers 1996). As Strathern notes, there may be insensitivity to intra-disciplinary differences and divisions in encounters where 'each expert becomes a representative of his or her discipline' (Strathern 2004: 5). Thus, it would be wrong to think that what is termed integration in environmental research is necessarily associated either in aspiration or in practice with the 'integrative-synthesis' mode of interdisciplinary research observed in other contexts (Barry and Born, introduction). For it can equally be associated with what we have termed the subordinationservice or agonistic-antagonistic modes of interdisciplinary research.

A second, quite different form of integration has been pursued at the Center for International Earth Science Information Network (CIESIN), one of the sub-centres of the Earth Institute. CIESIN's work pivots on data integration, employing geospatial information systems (GIS) to capture, store, edit, manage and share geographically-referenced information and associated attributes. This methodological use of spatiality makes it possible, as CIESIN researchers explained, to render commensurate disparate sets of data, including environmental information and social knowledge, providing the basis for discovering correlations between them that would otherwise go unnoticed. As a corollary, climate change researchers at CIESIN and elsewhere have to confront the problem of how to make data comparable, given the geographical unevenness and path-dependency of different national and local systems of measurement. The development of these practices has therefore been bound up with the necessary but uneven development of a global metrological zone that could inform the construction of global climate change models (Barry 2006; Edwards 2010).

A third practice of integration centres on the pursuit of mathematical models, particularly in the context of the development of the interdisciplinary fields of climate and earth system science (Edwards 2001, 2010; Wainwright 2009). This approach was particularly apparent at the Tyndall Centre. Tyndall's first director, John Schellnhuber, who came to the Centre from the Potsdam Institute for Climate Impact Research (PIK) in Germany, promoted a strong systems model approach in which society was understood as a combination of what Schellnhuber termed the 'anthroposphere' and the 'global subject': 
At the highest level of abstraction, the makeup of the Earth system $E$ can be represented by the following 'equation': $E=(N, H)(1)$ where $N=(a, b, c, \ldots) ; H=(A, S)$. This formula expresses the elementary insight that the overall system contains two main components, namely the ecosphere $N$ and the human factor $H . N$ consists of an alphabet of intricately linked planetary sub-spheres: $\boldsymbol{a}$ (atmosphere), $\boldsymbol{b}$ (biosphere), $\boldsymbol{c}$ (cryosphere; that is, all the frozen water of Earth), and so on. The human factor is even more subtle: $H$ embraces the 'physical' subcomponent $A$ ('anthroposphere' as the aggregate of all individual human lives, actions and products) and the 'metaphysical' sub-component $S$ reflecting the emergence of a 'global subject'. (Schellnhuber 1999: C20)

In practice, however, integration and modeling both served at the Tyndall Centre as boundary objects (Star and Griesemer 1989): ideas shared by different communities of practice but enacted differently across the Centre. While the notion of integration was commonly used by Tyndall Centre researchers, the Centre's different research groups adopted a variety of integration practices, mathematical modeling among them, but also forms of 'integration' involving users and non-experts. We associate a fourth practice of integration with these softer forms, which involved the use of focus groups and interviews as well modeling techniques. Indeed, within the Tyndall Centre there was reflexive debate about what was meant by 'integration' and what it might entail in practice. One researcher, for example, drew a contrast between two broad approaches to the integrated assessment of climate change (Rotmans 1998: 155; Tansey 2009). In the first, an interdisciplinary research team would seek to simulate the climate system as a whole, and subsequently report the results of their research to policy makers. In the second approach, however, which he favoured, a research team would develop policy options in conjunction with policy makers and stakeholders using participatory methods such as focus groups. The advantage of this latter approach was that, in principle, through the use of participatory methods, climate change models would be more closely attuned to the needs and concerns of policy-makers as they evolved over time. But the different practices of integration could also exist in agonistic relation to one another, as described by this Tyndall Centre researcher:

[ntegration] does have a formal definition within mathematical physics and computing; but here we use it in a more general sense of bringing together knowledge from diverse sources. Users' own integration of information may be either implicit (e.g. by ignoring or prioritising certain information), or it may be explicit, ranging from a lone policy analyst being asked to perform an analysis of literature on a certain issue to a policy-making organisation actually having its own in-house team of modellers. Integration may hence happen within the user organisation/network or through the interactions between the researcher and user, the processes interacting in complicated ways. (Haxeltine et al 2005: 19)

A fifth practice of integration evident in our institutional case studies was scenario work. Scenarios first emerged in the military domain, were subsequently applied in the corporate sector, and are now widely drawn upon as a method in academic research (van der Heijden 2005). In the institutions that we researched, scenarios tended to be valued on two grounds. On the one hand, it was claimed, they allow researchers and society 'to plan under uncertainty', by combining predictable and unpredictable elements (Anderson and Bows 2008). Indeed, uncertainty is generally held to be 'perhaps the most pervasive feature of climate scenarios' (Hulme and Dessai 2008). Scenarios were not intended to predict the future, but to raise questions about a range of possible futures (Robinson 1982, Anderson 2001). On the other hand, they gave quantitative data a kind of qualitative sheen through the 'narratives' and 'stories' generated by the scenario exercises (Arnell et al. 2004). In this way, scenario work was considered useful in so far as it generated workshops and discussions that brought together experts, stakeholders and various other publics (Funtowicz and Ravetz 1993; Owens 2000). This was necessary, it was reasoned, not only in order to render climate science accountable to society, but also in recognition of the way that human decisions, interests and judgments, including the conclusions of natural scientific research, enter into and affect the evolving phenomenon of climate change. 
For many environmental researchers integration appears to be demanded by the nature of the environment in itself. For the environment presents itself to researchers as a series of multidimensional problems, or as a complex system containing many distinct elements, stretched across time and space. In this account, integration refers to the process through which the contribution of many different experts and sources of data are brought together. However, for other researchers, including some of our informants, research on the environment poses more profound challenges. We contend that these challenges can be understood as ontological rather than primarily epistemological, organizational or technical. They are manifested in two ways.

First, some environmental researchers have come to be concerned with the ways in which environmental problems and objects are constituted (Castree 2005: 35). In our study, this concern was particularly evident at the Tyndall Centre. As we have seen, some researchers at the Centre explicitly argued that knowledge of environmental problems should be generated through the integrated involvement of researchers and stakeholders (O'Riordan 2004, Haxeltine et al 2005). This stance was captured, for example, in what some Centre researchers came to term the Interactive Integrated Assessment Process (IIAP):

The IIAP approach indicates that "knowledge" of what causes climate change, or how a given policy measure may affect future economies, societies and emissions of greenhouse gases, is a joint product of how the stakeholder judges the "worth" of the assessment models, or scenarios, and how the researcher judges what form of presentation of predictive outcomes will be most clear or helpful to the stakeholder. (Turnpenny et al 2005: 3)

The commitment to IIAP was explicitly guided by a desire to ensure that research had real implications for policy, and was based on the recognition that the concerns of policy makers were themselves situated within a political and organisational context, ensuring 'the acceptability and applicability of IAM [Integrated Assessment Methodology] in the policy arena' (Holman et al 2005). However, the idea of IIAP also conveys a sense that knowledge of climate change is more than a representation of a problem, but addresses how that problem is formed through a series of relations with others, including stakeholders. In this way, IIAP points toward the more general proposition that environmental problems do not exist independently of their problematisation. When viewed in this way, environmental research can be understood in the terms of what Lorraine Daston has called an 'applied metaphysics', one that - as noted in the Introduction to this book - contributes to and forms a part of, as well as analyzing, the world that it envisages. In coining the term applied metaphysics, Daston notes how phenomena such as 'dreams, atoms, monsters, culture, mortality, value, cytoplasmic particles, the self, tuberculosis can come into being and pass away' (2000: 1; see also Latour 1999). Daston's argument is a general one; in her account all scientific objects have a history: 'they grow more richly real as they become entangled in webs of cultural significance, material practices, and theoretical derivations' (2000: 13). ${ }^{33}$ Our argument is more specific: it is that environmental research has come explicitly to interrogate its own entanglement in the world that it analyses, concerning itself with the ways in which it needs to become 'more richly real' (Braun and Anderson 2008). The notion of IIAP proposed by Tyndall researchers can thus be understood as a novel way both of addressing and of managing this entanglement. But a similar 'applied metaphysics' underlay the use of scenarios by Tyndall researchers; for this in turn was based on a recognition of the difficulty of predicting the impacts of climate change due to the complex feedback between impacts, the production of knowledge about impacts, and the generation of policy responses that affected impacts. In effect, the task of the scenario builder was not to predict impacts at all, but to address the ways in which future impacts are affected by the outcome of a political process, within which the elaboration of scenarios played a part.

\footnotetext{
33 When introducing a series of 'biographies of scientific objects' Daston notes that 'these are not only stories about how interpretations of the world succeed one another, a vita contemplativa of scientific objects. They are also stories of the vita activa, of practices and products as concrete as the staging of individual atoms and the profits of insurance companies' (Daston 2000: 3, emphasis in original).
} 
A second manifestation of an incipient logic of ontology turns on calls for the involvement of affected populations in research on environmental problems including climate change (Adger et al. 2005, Thompson and Rayner 1998). Such developments have been driven by a sense of the potential contribution of non-experts to the production of scientific knowledge as well as by demands for greater accountability. However, they may also derive from a sense that environmental problems are not objectively given in nature, independently of the multiple ways in which they are encountered, created, experienced and valued (Hinchliffe 2001, Latour 2004, Jasanoff 2007, Whatmore, this volume). According to one Tyndall researcher involved in scenario development, for example, his approach is built on an explicitly value-driven assessment of future goals that leads to the reduction in the authority of professional elites and wider participation in planning process' (Anderson 2001). While for Mike Hulme, former Director of the Centre, 'our sensual experiences and scientific depictions of physical climates have historically been inexorably entangled with meanings reflecting broad cultural and ideological movements' (Hulme 2009: 355). In this account, the environment is recognized not only as a material formation but one that is aesthetically and affectively experienced; ${ }^{34}$ the importance of engaging non-experts in the research process may therefore arise from a conviction that their experience and knowledge forms part of what we mean by the environment (Whitehead 1920: 27-31, Halewood 2011). As Isabelle Stengers argues, 'It is not an objective definition of a virus or of a flood that we need, a detached definition everybody should accept, but the active participation of all those whose practice is engaged in multiple modes with the virus or with the river' (Stengers 2005: 1002, see also Gabrys and Yusoff 2012). However, an explicit concern with the realm of the experiential and the affective was quite marginal to the work of the research institutions at the centre of our study, even while it has increasingly become a focus for research in human and environmental geography (Lorimer 2007). Seen in the context of a concern with experience, the object of environmental research could be understood as a different kind of object from those typically encountered in the natural sciences - in fact, one that can no longer be characterized as an object at all' (Greco, this volume).

In light of these observations, the history of the Öko Institut is also instructive. For our research at the institute showed that the question of ontological transformation need not be understood as arising from scientific reflection, but resulted at least in part from an engaged ethical practice which was defined not in the first place through science. When the proto-Öko Institut researchers originally opted to turn against the 'phalanx of state and industry' to pursue a counter-science, they came to be embodiments not just of what science ought to be, but also of what one's relation to the environment as one's living environment and one's object of research - ought to be. At least some of them were primarily extending their critical personal ethics and ongoing environmental practice to their professional activities, rather than vice versa. The institute's founding moment may be seen to have entailed two things. First, a sudden eruption of a multiplicity of sciences, aligned with a variety of conflicting points of reference, including the state, on one hand, and society, on the other; and second, a relational reformulation of the research object that also includes the scientist him/herself in the relations it contains. Once again, in this context, the environment should be seen not only as an object of the institute's research, but as a contested and inherently relational field of problems.

\section{Conclusion}

Nowotny et al.'s notion that environmental research is 'strongly contextualised' and responsive to demands and signals from society is a provocative one. Indeed, for at least some of the researchers that we interviewed and observed, this analysis has been influential, whether as a public statement of a practice that they had themselves already developed, or as a guide to and a catalyst of their own emerging practice. Moreover, as we have seen, interdisciplinarity and transdisciplinarity have come to be qualities that are expected to be performed to research

\footnotetext{
${ }^{34}$ Whitehead pointed towards this conclusion in discussing the concept of nature when he notes that 'the red glow of the sunset should be as much part of nature as are the molecules and electric waves by which men of science would explain the phenomena' (Whitehead 1920: 29).
} 
funders and policy makers. In short, the social scientific analysis of interdisciplinarity and transdisciplinarity has rapidly come to enter into and inform the reality that it describes.

Yet if the problem of how to incorporate 'society' into research practice is critical to the interdisciplinary identity of some environmental research, there is no universal or general way in which this has been accomplished. Our study points to two conclusions. First, there has not been a straightforward movement towards greater 'contextualisation' or engagement with society. In practice, 'society' has been summoned into existence in multiple forms in different research contexts. While some social scientists have called for greater public participation in the environmental research process, in practice many interdisciplinary projects have engaged with society mainly through the mediation of its political representatives, or through established regulatory institutions. Indeed, in so far as it is oriented towards the solution of problems in environmental policy, interdisciplinary research may be particularly well attuned to the needs and concerns of policy makers. At the same time, there has been some movement towards the (re)introduction of academic forms of evaluation as a way of rendering research accountable to government. One question arising is therefore the extent to which relations with government and policy can really be equated with an engagement with 'society'.

Second, while environmental research appears to be a highly instrumental 'problem-focused' or applied field of research, it has also come to raise ontological questions. Given the proximity of academic environmental research to the much broader, extra-academic rethinking and re-practising of the environment, some researchers have been impelled to confront how their practice is woven into the constitution and evolution of the object of their research. In this sense, the environment does not exist as a given set of problems, but as a domain whose existence is bound up with shifting and conflicting engagements with it. As we have shown, environmental research has also begun to address the environment as something more than an object of natural scientific inquiry: as a domain of problems and processes that do not exist independently of the multiple ways in which they are valued and experienced. ${ }^{35}$

\section{References}

Acutt, N., A. Asghar, E. Boyd, A. Hartmann, J. Aeree Kim, I. Lorenzoni, M. Martell, A. Pyhala, and A. Winkels (2000). An Interdisciplinary Framework for Research on Global Environmental Issues. CSERGE Working Paper GEC 2000-23

http://www.uea.ac.uk/env/cserge/pub/wp/gec/gec_2000_23.pdf (accessed 10 December 2010)

Adger, W.N., Brown, K., Hulme, M., (2005). Redefining Global Environmental Change Global Environmental Change 15, 1-4.

Agar, J. (2008) 'What Happened in the Sixties’, British Journal of the History of Science, 41, 4: 567-600.

Agrawal, A. (2005) Environmentality: Technologies of government and the making of subjects. Durham and London: Duke University Press.

Anderson, K. (2001). Reconciling the electricity industry with sustainable development: backcasting a strategic alternative, Futures, 33: 607-623.

Anderson, K. A. Bows, S. Mander, S. Shackley, P. Agnolucci and P. Ekins (2006). 'Decarbonising Modern Societies: Integrated Scenarios Process and Workshops', Tyndall Centre Technical Report 48

\footnotetext{
35 Our thanks to Georgie Born, Mike Hulme, Eric Alliez, and Patrice Maniglier for their critical and constructive comments on our work.
} 
Anderson, K. and A. Bows (2008) 'Reframing the climate change challenge in light of post-2000 emission trends' Philosophical Transactions of the Royal Society - A: Mathematical, Physical and Engineering Sciences, 366: 3863-3882.

Anderson, K and B. Braun (eds.) (2008) Environment, Aldershot: Ashgate.

Argos, M., M.F. Parvez, A.Z.M.I. Hussain, H. Momotaj, R. Dhar A. van Geen, G.R. Howe, J.G. Graziano, H. Ahsan (2007). Influence of socioeconomic factors on the effects of arsenic on premalignant skin lesions - results from the Health Effects of Arsenic Longitudinal Study (HEALS). American Journal of Public Health 97: 825-831.

Barry, A. (2001). Political Machines: Governing a Technological Society, London: Athlone.

Barry, A. (2005). 'Pharmaceutical Matters: The Invention of Informed Materials'. Theory Culture Society 22, 1: 51-69.

Barry, A. (2006). ‘Technological Zones', European Journal of Social Theory, 9, 2: 239-253.

Barry, J. (1999). Environment and Social Theory. London and New York: Routledge.

Beck, U. (1992[1986]). Risk Society: Towards a New Modernity, London: Sage

Becker, E. (2003). Soziale Ökologie: Konturen und Konzepte einer neuen Wissenschaft. In Wissenschaftstheoretische Perspektiven für die Umweltwissenschaften. G. Matschonat and A. Gerber, eds. Wikersheim: Margraf Publishers.

Becker, E. and T. Jahn (2005). Societal Relations to Nature: Outline of a Critical Theory in the Ecological Crisis. (Published in German in Böhme, Gernot / Manzei, Alexandra (Ed.), Kritische Theorie der Technik und der Natur. 2003. München: Wilhelm Fink, 91-112)

http://www.isoe.de/english/person/reload.htm?thj.htm (accessed 6.02.2007)

Bergmann, M., B. Brohmann, E. Hoffmann, M. C. Loibl, R. Rehaag, E. Schramm, and J.-P. Voß (2005). Qualitätskriterien transdisziplinärer Forschung: Ein Leitfaden für die formative Evaluation von Forschungsprojekten. Frankfurt am Main: ISOE.

Bergmann, M. and T. Jahn (2008) 'CITY: mobil: A Model for Integration in Sustainability Research', in G. Hirsch Hadorn et al (eds), 89-102

Berglund, E. K. (1998). Knowing Nature, Knowing Science: An Ethnography of Local Environmental Activism. Cambridge: The White Horse Press.

Bhaskar, R, C.Frank, K.G. Høyer, P Næss and J Parker (eds.) (2010) Interdisciplinarity and Climate Chage: Transforming Knowledge and Practice for our Global Future, London: Routledge

Bird Rose, D. and L. Robin (2004) 'The Ecological Humanities in Action: an Invitation', Australian Humanities Review, 31-2, April, http://www.australianhumanitiesreview.org/archive/Issue-April2004/rose.html (accessed 4/1/12)

Boix Mansilla, V., I. Feller, and H. Gardner (2006). Quality assessment in interdisciplinary research and education. In Research Evaluation. April 2006: 69-74.

Bowler, P. (1992). The Environmental Sciences. New York and London: W.W. Norton \& Company. 
Bray, D. and H. von Storch (1999). Climate Science: An Empirical Example of Postnormal Science. In Bulletin of the American Meteorological Society 80(3): 439-455.

Bruce, A., et al. (2004). Interdisciplinary Integration in Europe: the case of the Fifth Framework programme. Futures 36(4):457-470.

Bulkeley, H. And P. Newell (2010) Governing Climate Change, London: Routledge

Callicott, J.B. (2010). 'The Environment' in R. Frodeman, J.T Klein and C. Mitcham (eds.) The Oxford Handbook of Interdisciplinarity, Oxford: Oxford University Press

Callon, M. P. Lascoumes and Y. Barthe. (2001). Agir dans un Monde Incertain: Essai sur la Démocratie Technique, Paris : Seuil

Cane, M.A. (1986). 'El Niño'. Annual Review of Earth and Planetary Sciences 14: 43-70.

Carter, N. (2001). The Politics of the Environment: Ideas, Activism, Policy. Cambridge: Cambridge University Press.

Castree, N. (2001). 'Socializing Nature: Theory, practice, and politics'. In Social Nature: Theory, practice, and politics. N. Castree and B. Braun, eds. Malden, MA, and Oxford: Blackwell.

Castree, N. (2005) Nature, London: Routledge

Castree, N., D. Demeritt, D. Liverman and B.Rhoads (eds) (2009) A Companion to Environmental Geography, Oxford: Basil Blackwell

Clark, W.C., P.J. Crutzen, and H.J. Schellnhuber (2004). Science for Global Sustainability: Toward a New Paradigm. In Earth System Analysis for Sustainability. H.J. Schellnhuber, P.J. Crutzen, W.C. Clark, M. Clausse, and H. Held, eds. Cambridge, MA: MIT Press.

Crow, M. and B. Bozeman (1998). Limited by Design: R\&D Laboratories in the U.S. National Innovation System. New York: Columbia University Press.

Daston, L. (2000) 'The Coming into Being of Scientific Objects', in L. Daston (ed.) Biographies of Scientific Objects (pp.1-14), Chicago: Chicago University Press.

Demeritt, D. (2001) 'The Construction of Global Warming and the Politics of Science', Annals of the Association of American Geographers, 91 (2): 307-337.

Descola, P. and G. Pálsson 1996. 'Introduction'. In Nature and Society: Anthropological perspectives. P. Descola and G. Pálsson, eds. London and New York: Routledge.

Dessai, S., W.N. Adger, M. Hulme, J. Turnpenny, J Köhler, and R. Warren, (2004), 'Defining and Experiencing Dangerous Climate Change', Climatic Change, 64: 11-25.

Diamond, J. (1997). Guns, Germs, and Steel: The Fate of Human Societies. New York: Norton \& Co.

Doherty, B. (2002). Ideas and Action in the Green Movement, London: Routledge.

Donaldson, A., N. Ward and S. Bradley (2010). Mess among disciplines: interdisciplinarity in environmental research. Environment and Planning A, 42: 1521-1536. 
Doubleday, R. (2007) 'Organizing accountability: co-production of technoscientific and social worlds in a nanoscience laboratory', Area, 39, 2, 166-175.

ECI (2003). Annual Review 2002-2003. Oxford: Environmental Change Institute, University of Oxford.

Edwards, P. (2001) 'Representing the Global Atmosphere: Computer Models, Data, and Knowledge about Climate Change', in C. Miller and P. Edwards, Changing the Atmosphere: Expert Knowledge and Environmental Governance (pp.31-66), Cambridge, MA: MIT press.

Edwards, P. (2010) A Vast Machine: Computer Models, Climate Data, and the Politics of Global Warming, Cambridge, MA: MIT press.

ESRC (2000) Annual Report 1999-2000, Swindon: ESRC.

Ewen, C., F. Ebinger, C.-O. Gensch, R. Grießhammer, C. Hochfeld, V. Wollny (1997).

HöchstNachhaltig: Sustainable Development - Vom Leitbild zum Werkęeng. Freiburg: Öko-Institut.

Foucault, M. (2000) 'Questions on Method', in Michel Foucault: Essential Works 1954-1984 (pp.223-238). London: Penguin.

Funtowicz, S. O. and J. R. Ravetz 1993. 'Science for the Post-Normal Age'. Futures 25, 739-755.

Gabrys, J. and Yusoff, K. (2012) 'Arts, Sciences and Climate Change: Practices and Politics at the Threshold', Science as Culture, 21 (1): 1-24.

Gibbons, M., C. Limoges, H. Nowotny, S. Schwartzman, P. Scott and M. Trow (1994). The New Production of Knowledge: The Dynamics of Science and Research in Contemporary Societies. London: Sage.

Goodess, C. M., Hanson, C., Hulme, M. \& Osborn, T. J. (2003) 'Representing climate and extreme weather events in integrated assessment models: a review of existing methods and options for development'. Integr. Assess. 4, 145-171.

Grove, R. (1995). Green Imperialism: Colonial Expansion, Tropical Island Edens, and the Origins of Environmentalism, 1600-1860, Cambridge: Cambridge University Press.

Guggenheim, M. (2006) 'Undisciplined Research: Structures of Transdisciplinary Research', Science and Public Policy 33(6): 394-398

Hacking, I. (2002) Historical Ontology, Cambridge, MA: Harvard University Press.

Halewood, M. (2011) A. N. Whitehead and Social Theory: Tracing a Culture of Thought, London: Anthem.

Haraway, D. (1991) Simians, Cyborgs and Women: The Reinvention of Nature. New York; Routledge.

Harrison, S. et al. (2004) Thinking across the divide: perspectives on the conversations between physical and human geography Area 36: 435-442

Harvey, D. (2011) The Enigma of Capital and the Crisis of Capitalism, London: Profile.

Haxaltine, A, J. Turnpenny, T. O'Riordan and R. Warren (2005) 'The creation of a pilot phase Interactive Integrated Assessment Process for managing climate futures', Tyndall Technical Report 31, $58 \mathrm{pp}$. 
Hinchliffe, S. (2007) Geographies of Nature: Societies, Environments, Ecologies, London: Sage.

Hirsch Hadorn G., Hoffmann-Riem, H., Biber-Klemm, S., Grossenbacher-Mansuy, W., Joye, D., Pohl, C., Wiesmann, U., Zemp, E. (eds.) (2008) Handbook of Transdisciplinary Research, Berlin: Springer.

HM Treasury (2006) Science and Innovation Investment Framework 2004-2014: the Next Steps, London: HMSO.

Holman, I., Rounsevell, M., Shackley, S., Harrison, H., Nicholls, R., Berry, P. and Audsley, E. (2005) 'A regional, multi-sectoral and integrated assessment of the impacts of climate and socio-economic change in the UK: Part I. Methodology', Climatic Change, 71, 9-41.

House of Commons (2006a) Select Committee on Science and Technology, Examination of Witnesses, $12^{\text {th }}$ December, http://www.parliament.the-stationeryoffice.co.uk $/ \mathrm{pa} / \mathrm{cm} 200607 / \mathrm{cmselect} / \mathrm{cmsctech} / 68 / 6121203 . \mathrm{htm}$

House of Commons (2006b) Select Committee on Science and Technology, Memorandum from the Tyndall Centre for Climate Change Research, http://www.publications.parliament.uk/pa/cm200607/cmselect/cmsctech/68/68we10.htm

Hulme, M. (2008) 'Geographical Work at the Boundaries of Climate Change', Trans Inst Br Geogr NS, 33, 5-11.

Hulme, M. (2009) Why We Disagree About Climate Change: Understanding Controversy, Inaction and Opportunity, Cambridge: Cambridge University Press.

Hulme, M. and S. Dessai (2008) 'Negotiating Future Climates for Public Policy: a Critical Assessment of the Development of Climate Scenarios for the UK', Environmental Science and Policy, 11, 1, 54-70.

Hulme, M. and A. Minns (2006) 'Truly Useful: Doing climate change research that is useful for both theory and practice: Tyndall Briefing Note 14'.

http://www.tyndall.ac.uk/sites/default/files/TrulyUsefulTyndall.pdf (accessed 10 December 2010)

Jahn, T. (2003). Sozial-ökologische Forschung - Ein neuer Forschungstyp in der

Nachhaltigkeitsforschung. In Handbuch Nachbaltige Entwicklung. Wie ist nachbaltiges Wirtschaften machbar? G. Linne and M. Schwarz, eds. Pp. 545-555. Opladen: Leske + Budrich.

Jasanoff, S. (1994) 'The Idiom of Co-Production', in Jasanoff (ed.) States of Knowledge: the Co-Production of Science and Social Order, London: Routledge.

Jasanoff, S. and Wynne, B. (1998) 'Science and Decisionmaking' in Rayner and Malone (eds.) (1998b): $1-88$.

Kates, R., Ausubel, J. and Berberian, M. (eds)(1985). Climate Impact Assessment. http://www.icsuscope.org/downloadpubs/scope27 (accessed 12 December 2010),

Knorr-Cetina, K. (1999). Epistemic Cultures: How the Sciences Make Knowledge. Cambridge, MA: Harvard University Press.

Komiyama, H. and Takeuchi, K. (2006) 'Sustainability Science - Building a New Discipline', Sustainability Science, 1, 1, 1-6. 
Krohn, P. (1995) 'Solly Zuckerman Baron Zuckerman, of Burnham Thorpe, O. M., K. C. B. 30 May 1904-1 April 1993', Biogr. Mems Fell. R. Soc. 41, 576-598.

Lamb, H. (1982) Climate, History and the Modern World, London: Methuen.

Lamont, M. (2009) How Professors Think: Inside the Curious World of Academic Judgement, Cambridge, MA: Harvard University Press.

Latour, B. (1993) We Have Never Been Modern, Hemel Hempstead: Harvester Wheatsheaf.

Latour, B. (1999) Pandora's Hope: Essays on the Reality of the Sciences, Cambridge, MA: Harvard University Press.

Latour, B. (2004) The Politics of Nature, Cambridge, MA: Harvard University Press.

Law, J. and Singleton, V. (2005) 'Object Lessons’. Organization 12(3): 331-355.

Liverman, D. (1999). Geography and the Global Environment. Annals of the Association of American Geographers 89(1): 107-120.

Livingstone, D. N. (1992). The Geographical Tradition: Episodes in the History of a Contested Enterprise. Oxford and Cambridge, M.A.: Blackwell.

Lorimer, J. (2007) 'Nonhuman charisma', Environment and Planning D: Society and Space, 25 (5): 911 - 932.

Lowe, P. and P. Phillipson (2009) 'Barriers to research collaboration across disciplines:

scientific paradigms and institutional practice', Environment and Planning A, 41, 1171-1184.

Luke, T. 2006 (1995). 'On Environmentality: Geo-Power and Eco-Knowledge in the Discourses of Contemporary Environmentalism'. In N. Haenn and R.R. Wilk (eds.)_The Environment in Anthropology: A Reader in Ecology, Culture, and Sustainable Living. New York and London: New York University Press.

Mackinder, H. (1962 [1887]) 'The Scope and Methods of Geography' Proceedings of the Royal Geographical Society, 9, 141-60, in Democratic Ideals and Reality, Westport: Greenwood Press.

Maasen, S., Lengwiler, M. and M. Guggenheim (2006) Practices of transdisciplinary research: close(r) encounters of science and society. In Science and Public Policy 33 (6): 394-398.

Miller, C. and P. Edwards (2001) Changing the Atmosphere: Expert Knowledge and Environmental Governance, Cambridge, MA: MIT Press.

Mitchell, T. (2011) Carbon Democracy: Political Power in the Age of Oil, London: Verso.

Monbiot, G. (2006). The threat is from those who accept climate change, not those who deny it. (The Guardian $21^{\text {st }}$ September, www.guardian.co.uk/commentisfree/2006/sep/21/comment.georgemonbiot (accessed 12/12/10)

Nature (2006) 'Special provision: some research centres are more equal than others', Nature, 441, 7090, 127-128.

Nowotny, H. (1976) 'Social Aspects of the Nuclear Power Controversy' European Centre for Social Welfare Trainging and Research and the Joint IAEA/IIASA Research Project, Research Memorandum, RM-76-33, 29pp, www.iiasa.ac.at/Admin/PUB/Documents/RM-76-033.pdf (accessed 4 January 2012). 
Nowotny, H. (1979) 'Science and its Critics: Reflections on Anti-Science', In H. Nowotny and H. Rose (eds.), Counter-Movements in the Sciences: the Sociology of Alternatives to Big Science (pp.1-26), Dordrecht: D. Reidel.

Nowotny, H., P. Scott, and M. Gibbons (2001) Re-Tbinking Science: Knowledge and the Public in an Age of Uncertainty. Cambridge: Polity.

O'Riordan, T. (2004) 'Environmental science, sustainability and politics', Transactions of the Institute of British Geographers 29(2): 234-247.

Osborne, T. (2004). 'On mediators: intellectuals and the ideas trade in the knowledge society', Economy and Society, 33 (4): 430-447.

Owens, S. (2000). Commentary. 'Engaging the public': information and deliberation in environmental policy', Environment and Planning A, 32: 1141-1148.

Petts, J., S. Owens, and H. Bulkeley (2004). Discussion Paper for Seminar 6. ESRC Transdisciplinary Seminar Series: 'Knowledge and Power: Exploring the Science/Society Interface in the Urban Environment Context', University of Birmingham and University of Cambridge, UK.

Power, M. (1997). The Audit Society: Rituals of Verification. Oxford: Oxford University Press.

Rayner, S. (1992) Global Environmental Change: Understanding the Human Dimensions. In Environment: Science and Policy for Sustainable Development 34(7): 25-28.

Rayner, S. and E.L. Malone (eds) (1998a) Human Choice and Climate Change (4 Vols). Battelle Press: Columbus, Ohio.

Rayner, S. and E.L. Malone (1998b) Introduction. In S. Rayner and E.L. Malone (eds), Human Choice and Climate Change: The Societal Framework (Vol. 1). Battelle Press: Columbus, Ohio.

Rayner, S. and E.L. Malone (1998c) The challenge of climate change to the social sciences. In S. Rayner and E.L. Malone (eds), Human Choice and Climate Change: What Have We Learned? (Vol. 4). Battelle Press: Columbus, Ohio.

Rittel, H. and M. Webber (1973) 'Dilemmas in a general theory of planning', Policy Sciences, 4: 155-169.

Robinson, J. (1982) 'Energy backcasting: a proposed method of policy analysis' 10, 4: 337-344.

Roose, J. (2002) Made by Öko-Institut: Wissenschaft in einer bewegten Umwelt. Freiburg: Öko-Institut.

Rotmans, J. (1998) 'Methods of IA: the Challenges and Opportunities Ahead', Environmental Modeling and Assessment, 3, 155-179.

Sachs, J. (2000) “Tropical Underdevelopment.” prepared for Economic History Association Annual Meeting, September 2000 and CID Working Paper No. 57, December 2000

(http://www.cid.harvard.edu/cidwp/057.htm, last accessed 21 January 2012)

Sachs, J. (2003). Institutions Don't Rule: Direct Effects of Geography on Per Capita Income. Working Paper 9490, National Bureau of Economic Research, Cambridge, MA

(http://www.nber.org/papers/w9490, last accessed 21 January 2012) 
Sachs, J. (2005) The End of Poverty. London: Penguin Books.

Sachs, J et al (2009) Biodiversity Conservation and the Millennium Development Goals, Science, 18 September, 325, 5947: 1502-1503.

Sachs, W. (1995). Zählen oder Erzählen? Natur- und geisteswissenschaftliche Argumente in der Studie "Zukunftsfähiges Deutschland”. Wechselwirkung 76: 20-25.

Saloranta, T. (2001) 'Post-Normal Science and the Global Climate Change Issue', Climatic Change 50: 395-404.

SCA (2010). 'Natureculture: entangled relations of multiplicity', Society for Cultural Anthropology Spring 2010 Meeting. Santa Fe, NM. (http://sca.culanth.org/meetings/sca/2010/intro.html, last accessed 14 March 2012).

Schellnhuber, H-J (1999) 'Earth Systems Analysis and the Second Copernican Revolution', Nature supplement, 402 ( $2^{\text {nd }}$ December), 19-23.

Schellnhuber, H-J. (2004) Earth System Analysis for Sustainability, Cambridge, MA. MIT press.

Schröder, H. (2010) The History of International Climate Change Politics: Three Decades of Progress, Process and Procrastination, in M. Boykoff (ed.) The Politics of Climate Change: a Survey (pp.26-41), London: Routledge.

Star, S.L. and J. Giesemer (1989). Institutional Ecology, 'Translations' and Boundary Objects: Amateurs and Professionals in Berkeley's Museum of Vertebrate Zoology, 1907-39 Social Studies of Science, 19 (3): 387-420.

Stengers, I. (2005) 'The Cosmopolitical Proposal', in B. Latour and P.Weibel (eds.) Making things Public: Atmospheres of Democracy (pp.94-1003), Cambridge, MA: MIT Press.

Strang, V. (2009) 'Integrating the social and natural sciences in environmental research: a discussion paper', Journal of Environment, Development and Sustainability, 11: 1-18.

Strathern, M. (1991). Partial Connections. Savage, Maryland: Rowman \& Littlefield.

Strathern, M. (1992). After Nature: English Kinship in the Late Twentieth Century. Cambridge: Cambridge University Press.

Strathern, M. (1999) Property, Substance, and Effect, London: Athlone.

Strathern, M. (2000) 'Accountability ....and ethnography'. In M. Strathern (ed.), Audit Cultures: Anthropological Studies in Accountability, Ethics, and the Academy. London and New York: Routledge.

Strathern, M. (2004). Commons and Borderlands: Working Papers on Interdisciplinarity, Accountability and the Flow of Knowledge. Oxon: Sean Kingston.

Tansey, J. (2009) 'Integrated Assessment' in N. Castree, D. Demeritt, D. Liverman and B. Rhoads (eds.) A Companion to Environmental Geography (pp.357-369), Oxford: Wiley-Blackwell.

Tompkins, E. (2005) 'Review of Interdisciplinary Environmental Centres of Excellence', report to MISTRA, Swedish Foundation for Strategic Environmental Research, http://www.mistra.org/download/18.61632b5e117dec92f47800097871/Tompkins+report.pdf 
(last accessed 5 January 2012).

Turney, J. (2005) 'Gaia: nice is not enough', Interdisciplinary Science Reviews 30(1): 1-6.

Turnpenny, J. (2003). 'Post-Normal Science and the Tyndall Centre: some critical issues: Tyndall Briefing Note 9'. http://www.tyndall.ac.uk/sites/default/files/note09.pdf (accessed 12 December 2010)

Turnpenny, J, A. Haxeltine, I. Lorenzoni, T. O'Riordan, and M. Jones (2005) 'Mapping actors involved in climate change policy networks in the UK', Tyndall working paper 66, pp.13.

Turnpenny, J. and T. O'Riordan (2007). Putting Sustainability Science to Work: Assisting the East of England to Respond to the Challenges of Climate Change, Transactions of the Institute of British Geographers, 32: 102-105.

Tyndall Centre (2000) 'The Tyndall Centre for Climate Change Research: Integrated Research for Sustainable Solutions', final proposal, February, pp.99.

Tyndall Centre (2006), Memorandam for the Tyndall Centre for Climate Change Research, House of Commons Select Committee on Science and Technology, written evidence.

Van der Heijden, K. (2005) Scenarios: The Art of Strategic Conversation. Chichester: John Wiley \& Sons.

Viveiros de Castro, E. (1998) 'Cosmological Deixis and Amerindian Perspectivism', in JRAI 4(3): 469488.

Von Weizsäcker, E.U. (1997 [1989]) Erdpolitik (5 ${ }^{\text {th }}$ edition), Darmstadt: Primus.

Wainwright, J. (2009) 'Earth-System Science', in N. Castree, D. Demeritt, D. Liverman and B. Rhoads (eds.) A Companion to Environmental Geography (pp.145-167), Oxford: Wiley-Blackwell.

Watts, M. and R. Peet (2004) 'Liberating Political Ecology', in R. Peet and M. Watts (eds.) Liberation Ecologies: Environment, Development, Social Movements, $2^{\text {nd }}$ edition (pp.3-47), London: Routledge.

Weszkalnys, G. (2010) Berlin, Alexanderplatr: Transforming place in a unified Germany. Oxford and New York: Berghahn.

Whatmore, S. (2002) Hybrid Geographies: Natures, Cultures, Spaces, London: Sage.

Whatmore, S. (2009). Mapping knowledge controversies: science, democracy and the redistribution of expertise. Progress in Human Geography 33(5): 587-598.

Whitehead, A.N. (1920) The Concept of Nature, Cambridge: Cambridge University Press

Whitehead, M. R. Jones and M. Jones (2007) The Nature of the State: Excavating the Political Ecologies of the Modern State, Oxford: Oxford University Press.

Wissenschaftsrat 2000. Thesen zur künftigen Entwicklung des Wissenschaftssystems in Deutschland. http://www.wissenschaftsrat.de/texte/4594-00.pdf (accessed 12 February 2007)

Zebiak, S.E. and M.A. Cane (1987). 'A Model El-Niño Southern Oscillation', Monthly Weather Review, 115, 10: 2262-2278. 
